\title{
An Unusual Back Muscle Identified Bilaterally: Case Report
}

\author{
Juan J. Altafulla ${ }^{1}$, Mayank Patel ${ }^{2}$, R. Shane Tubbs ${ }^{3}$, Joe Iwanaga ${ }^{4}$, Zachary Litvack ${ }^{5}$
}

1. SNI, Seattle Science Foundation, Seattle, USA 2. Clinical Anatomy Research, Seattle Science Foundation, Seattle, USA 3. Neurosurgery, Seattle Science Foundation, Seattle, USA 4. Seattle Science Foundation, Seattle, USA 5. Neurosurgery, Swedish Neuroscience Institute, Seattle, USA

Corresponding author: Juan J. Altafulla, juanaltafulla.md@gmail.com

\section{Abstract}

Most muscular structures in the human body are named based on their function, origin/insertion, or shape. During routine dissection of the back, an unusual muscle was found deep to the rhomboid muscles. The details of this case and a review of the extant literature are provided.

Categories: Physical Medicine \& Rehabilitation, Neurosurgery, Orthopedics

Keywords: variation, ribs, respiration, anomaly, myology, serratus posterior superior

\section{Introduction}

The serratus posterior superior (SPS) muscle arises as a thin aponeurosis from the lower part of the nuchal ligament, the spinous processes of the seventh cervical, and first two thoracic vertebrae and adjacent supraspinous ligaments [1]. It follows a lateral course ending as four digitations that insert lateral to the angle of the third, fourth, and fifth ribs [2]. Traditionally, the SPS and the serratus posterior inferior (SPI) have been thought to act as accessory respiratory muscles [3, 4]. However, this function has not been supported by electromyography studies $[5,6]$.

Herein, we report the bilateral occurrence of an unusual muscle of the back found during routine dissection and compare it to other reports in the literature.

\section{Case Presentation}

During routine dissection of a male cadaver aged 59-year-old at death, an unusual muscle was identified on the back. The muscle was deep to the rhomboids, superficial to the erector spinae and was more or less vertically arranged. The origin of the muscle was from the spinous processes of the lower cervical vertebrae and the insertion was onto the second through sixth ribs (Figure 1). The innervation and blood supply were via the intercostal nerve and artery, respectively.

Received 05/22/2018

Review began 06/04/2018 Review ended 06/13/2018 Published 06/15/2018

○ Copyright 2018

Altafulla et al. This is an open access article distributed under the terms of the Creative Commons Attribution License CC-BY 30 , which permits unrestricted use, distribution, and reproduction in any medium, provided the original author and source are credited.

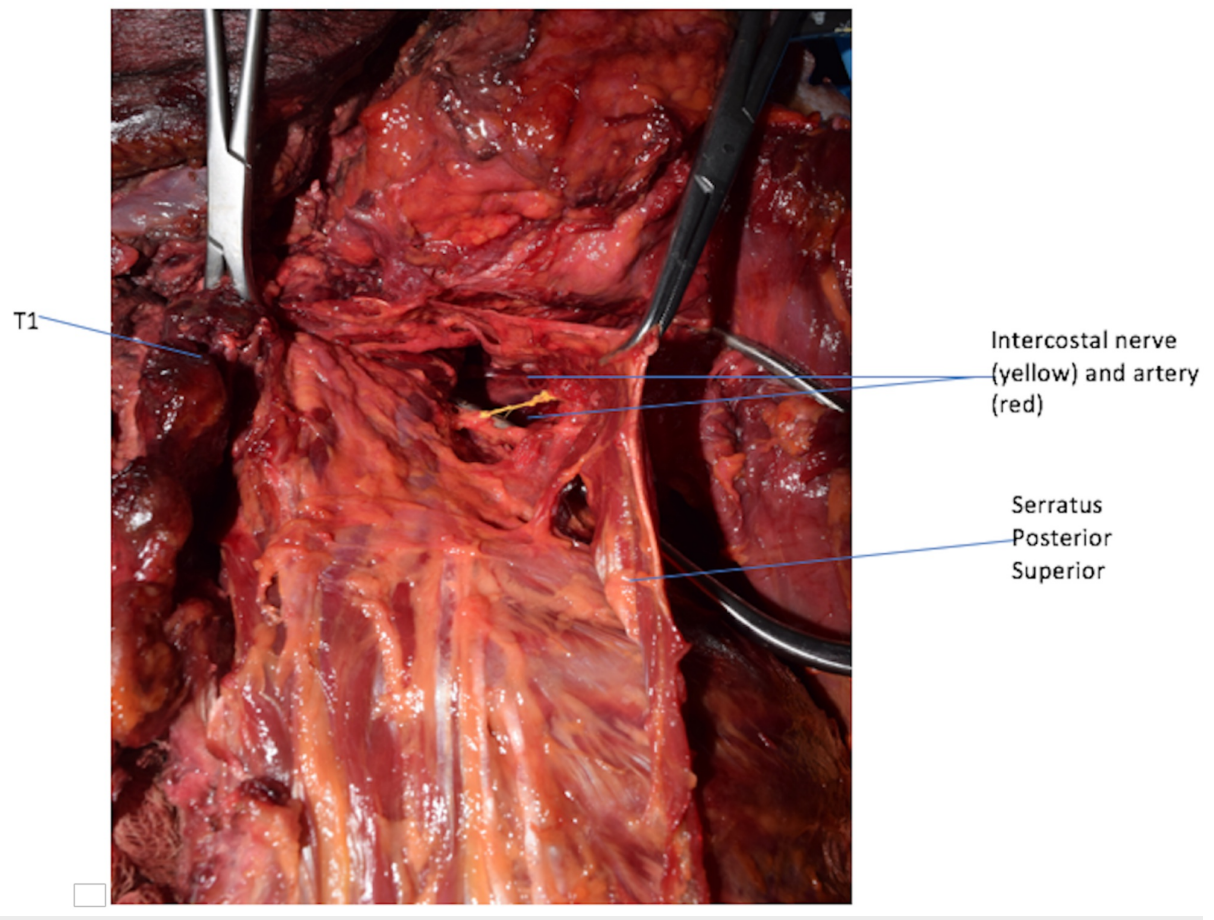




\section{Cureus}

\section{FIGURE 1: Serratus Posterior Superior.}

Serratus Posterior Superior with its underlying vascular and nerve supply.

Left: medial; right: lateral; up: cephalic; down: caudal.

Although the fiber direction and number of rib attachments were not consistent with the SPS, the position of the muscle between the rhomboids and erector spinae indicated that this muscle most likely represented an unusual variation of the SPS (Figure 2). No other anatomical variations were found on the back and no pathology such as scoliosis was identified.

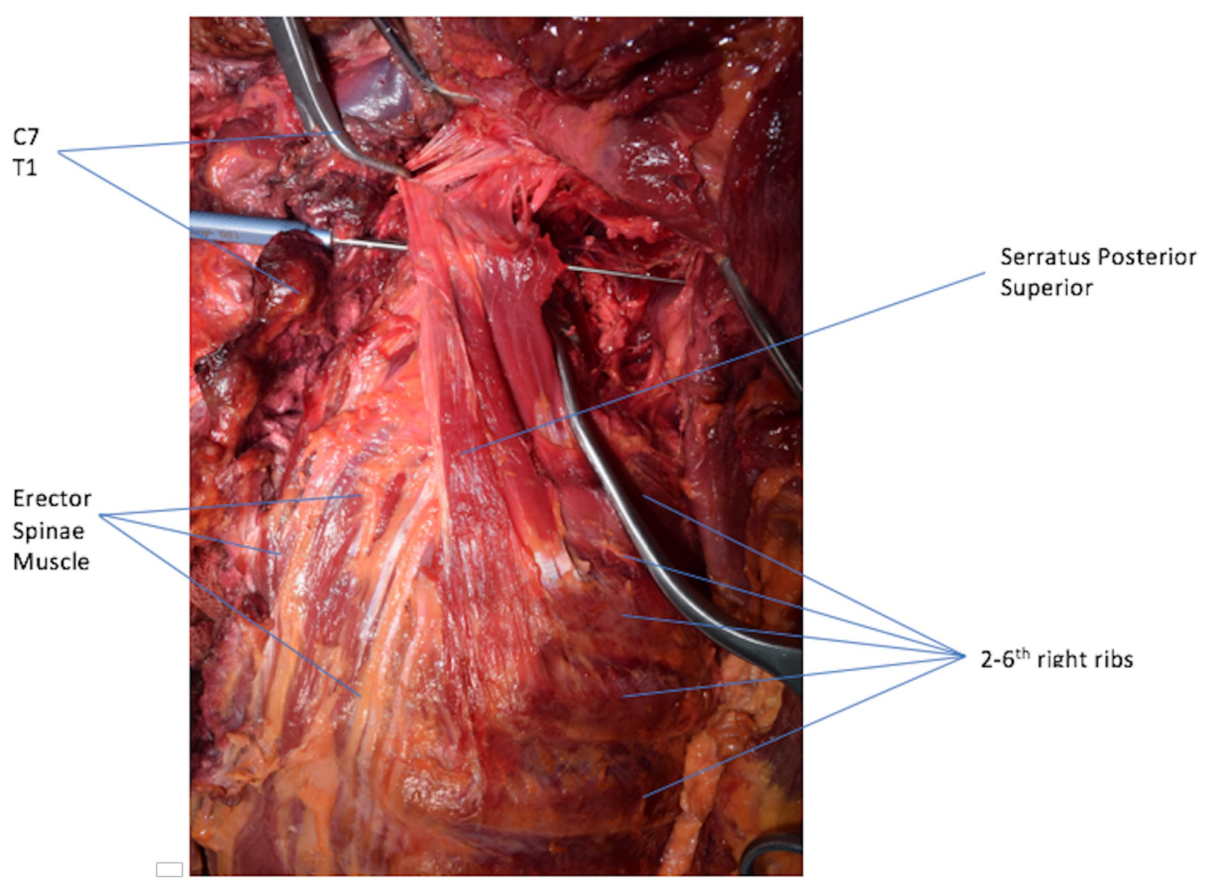

FIGURE 2: Back Muscles.

Serratus Posterior Superior running in a vertical fashion.

Left: medial; right: lateral; up: cephalic; down: caudal.

\section{Discussion}

The present case depicts a variation of one of the back muscles, the SPS. A small number of variations have been reported in the literature for the serratus posterior muscles with most of these in regard to the number of ribs that they attach to. Most cases have reported a range from three to six digitations that can extend from as high as C4 all the way down to T5 [1]. Rarely, the SPS can be absent or have attachment to other regional muscles such as the erector spinae [1]. Typically, this muscle has an oblique orientation. However, in our case, the fibers of the muscle were more or less vertical in nature.

Multiple functions have been attributed to the SPS and SPI from aiding in inspiration to having a proprioceptive function [7]. Regarding a respiratory function, Loukas et al. [8] evaluated the SPS and SPI in 50 adult cadavers. Eighteen of the specimens had a history of chronic obstructive pulmonary disease. However, in this latter cohort, there were no statistically significant differences between sides, race, sex, or age in regard to the dimensions of these muscles. As one would expect hypertrophy of accessory respiratory muscles in patients with obstructive respiratory disease, these authors concluded that based on their anatomical study, the SPS and SPI are not involved in respiration.

Additionally, improved imaging modalities and embryological knowledge will hopefully, in the future, better elucidate the function of such muscle variations of the back [9-13].

\section{Conclusions}


Although it is not clear what function such a thin, vertically arranged muscle might have, as seen in our case, documenting such muscular variations is important from an archival and future study perspective.

\section{Additional Information \\ Disclosures}

Human subjects: Consent was obtained by all participants in this study. Conflicts of interest: In compliance with the ICMJE uniform disclosure form, all authors declare the following: Payment/services info: All authors have declared that no financial support was received from any organization for the submitted work. Financial relationships: All authors have declared that they have no financial relationships at present or within the previous three years with any organizations that might have an interest in the submitted work. Other relationships: All authors have declared that there are no other relationships or activities that could appear to have influenced the submitted work.

\section{References}

1. Bakkum BW, Miller N: Back muscles. Bergman's Comprehensive Encyclopedia of Human Anatomic Variation. Tubbs RS, Shoja MM, Loukas M (ed): John Wiley \& Sons, Inc., 2016. 10.1002/9781118430309.ch30

2. Standring S, Borley NR: Gray's Anatomy: The Anatomical Basis of Clinical Practice. Churchill Livingstone/Elsevier, 2008.

3. Moore KL, Dalley AF, Agur AMR: Clinically Oriented Anatomy. Lippincott Williams \& Wilkins, 2006.

4. Rosse C, Hollingshead WH, Gaddum-Rosse P: Hollinshead's Textbook of Anatomy. Harper \& Row, Philadelphia; 1985.

5. Orozco-Levi M: Structure and function of the respiratory muscles in patients with COPD: impairment or adaptation?. Eur Res J. 2003, 22:41-51. 10.1183/09031936.03.00004607

6. Polla B, D’Antona G, Bottinelli R, Reggiani C: Respiratory muscle fibres: specialisation and plasticity. Thorax. 2004, 59:808-817. 10.1136/thx.2003.009894

7. Vilensky JA, Baltes M, Weikel L, Fortin JD, Fourie LJ: Serratus posterior muscles: anatomy, clinical relevance, and function. Clin Anat. 2001, 14:237-241. 10.1002/ca.1039

8. Loukas M, Louis RG, Wartmann CT, Tubbs RS, Gupta AA, Apaydin N, Jordan R: An anatomic investigation of the serratus posterior superior and serratus posterior inferior muscles. Surg Radiol Anat. 2008, 30:119-123. 10.1007/s00276-008-0305-X

9. Creze M, Soubeyrand M, Yue JL, Gagey O, Maitre X, Bellin MF: Magnetic resonance elastography of the lumbar back muscles: a preliminary study. Clin Anat. 2018, 31:514-520. 10.1002/ca.23065

10. Creze M, Nyangoh Timoh K, Gagey O, Rocher L, Bellin MF, Soubeyrand M: Feasibility assessment of shear wave elastography to lumbar back muscles: a radioanatomic study. Clin Anat. 2017, 30:774-780. 10.1002/ca.22903

11. Mekonen HK, Hikspoors JP, Mommen G, Eleonore KÖhler S, Lamers WH: Development of the epaxial muscles in the human embryo. Clin Anat. 2016, 29:1031-1045. 10.1002/ca.22775

12. Shen XH, Xue HD, Chen Y, Wang M, Mirjalili SA, Zhang ZH, Ma C: A reassessment of cervical surface anatomy via CT scan in an adult population. Clin Anat. 2017, 30:330-335. 10.1002/ca.22847

13. Au J, Perriman DM, Pickering MR, Buirski G, Smith PN, Webb AL: Magnetic resonance imaging atlas of the cervical spine musculature. Clin Anat. 2016, 29:643-659. 10.1002/ca.22731 